\title{
Reciprocal synergy between Escherichia coli and Bacteroides fragilis in an intra-abdominal infection model
}

\author{
O. D. ROTSTEIN*, J. KAO and KIMBERLY HOUSTON
}

\section{Department of Surgery and Institute of Medical Science, University of Toronto and Toronto General Hospital, Toronto, Canada}

\begin{abstract}
Summary. The synergic relationship between Escherichia coli and Bacteroides fragilis was examined in a model of intra-abdominal abscess formation. The addition of $\boldsymbol{B}$. fragilis to $E$. coli in the fibrin clot inoculum increased abscess weight and residual numbers of $E$. coli in the abscess at 7 days. In a reciprocal fashion, $E$. col $i$ was capable of enhancing $B$. fragilis persistence in abscesses. Neither heat-killed $E$. coli nor heatkilled $B$. fragilis was able to mimic the synergic effect of its live counterpart. Furthermore, $B$. fragilis culture filtrate was unable to reproduce the ability of live $B$. fragilis to act synergically with $E$. coli. For $B$. fragilis to act synergically with $E$. coli, it had to be inoculated locally with $E$. coli in the peritoneal cavity, indicating that an effect on systemic resistance by $B$. fragilis was an unlikely mechanism for the production of bacterial synergy. These studies suggest that the synergic relationship between bacteria in polymicrobial infections is a complex one, resulting from intimate interactions between bacteria and the host in the local milieu of the infection.
\end{abstract}

\section{Introduction}

The microbial flora of peritonitis resulting from perforation of the lower gastrointestinal tract consists of a mixture of aerobic and anaerobic bacteria (Lorber and Swenson, 1975). Several studies have demonstrated the importance of directing antimicrobial therapy against both components of the polymicrobial flora in the management of intra-abdominal infection (Berne et al., 1982; Gorbach, 1984). However, much remains to be learned about the interactions between aerobic and anaerobic bacteria in determining the detailed pathogenesis of these infections.

The purpose of these studies was to examine potential mechanisms of pathogenic synergy between Escherichia coli and Bacteroides fragilis in vivo. Most studies of bacterial synergy have employed subcutaneous infection models (Kelly, 1978; Brook et al., 1984; MacLaren et al., 1984; Verweijvan Vught et al., 1985). Host defence mechanisms in these infections differ markedly from those active in the peritoneal cavity (Delong and Simmons,

Received 3 Aug. 1988; revised version accepted 16 Feb. 1989.

* Correspondence should be sent to: Dr O. D. Rotstein, Toronto General Hospital, 200 Elizabeth Street, Eaton North, 7-234 Toronto, Ontario, M5G 2C4, Canada.
1982; Dunn et al., 1987). As a result, conclusions derived from these studies may not pertain directly to the setting of intra-abdominal infection. Onderdonk et al. (1976) clearly established the synergic relationship between $E$. coli and $B$. fragilis in an intra-abdominal infection model. However, subsequent studies have focused on the mechanisms by which $B$. fragilis capsular polysaccharide induces abscess formation (Onderdonk et al., 1977; Shapiro et al., 1982, 1986). In the present studies, the mechanisms of $E$. coli-B. fragilis interactions were examined in an intra-abdominal model of mixed infection to closely mimic the clinical setting. Using this model, we have previously shown bacterial synergy between $E$. coli and $B$. fragilis with respect to lethality and abscess formation (Rotstein et al., 1987; Rotstein and Kao, 1988). The initial inoculum of $E$. coli in the bacterial mixture was the prime determinant of whether synergic lethality or abscess formation occurred. With a high $E$. coli inoculum ( $>10^{8} \mathrm{cfu}$ ), the addition of $B$. fragilis to $E$. coli resulted in an enhanced mortality rate compared to that resulting from inoculation of either organism alone. At a lower $E$. coli inoculum $\left(<10^{8} \mathrm{cfu}\right)$, the combination of $E$. coli plus $B$. fragilis rarely caused death but resulted in synergic abscess formation. In this report, the reciprocal nature of the synergic relationship between $E$. coli and $B$. fragilis is 
explored and the characteristics of this interaction are further defined.

\section{Materials and methods}

\section{Bacterial strains and growth conditions}

A serum-resistant strain of E. coli, 00 , isolated from a patient at the University of Minnesota Hospitals and a strain of $B$. fragilis, VPI 9032, obtained from Dr T. D. Wilkins, Virginia Polytechnic Institute and State University (VPI), Blacksburg, VA, were used in these studies. Techniques of storage, growth conditions, medium ingredients and methods of enumeration have been previously described (Namavar et al., 1983; Rotstein et al., 1987).

For inoculation into the fibrin clot, the $B$. fragilis culture was pelleted by centrifugation at $1600 \mathrm{~g}$ for 10 min, and resuspended in pre-reduced Hanks's Balanced Salts Solution (HBSS, Gibco, Grand Island, NY) supplemented with cysteine hydrochloride (Sigma Chemical Company, St Louis, MO) $0.5 \mathrm{mg} / \mathrm{L}$.

\section{Incorporation of bacteria into fibrin clots}

Human fibrinogen (Sigma) $2 \mathrm{~g} / \mathrm{L}$ was sterilised with ultraviolet light for $10 \mathrm{~min}$. For preparation of infected clots, $1.4 \mathrm{ml}$ of fibrinogen was added to a $75 \times 12 \mathrm{~mm}$ polystyrene tube in an anaerobic chamber. Either $E$. coli in $0.2 \mathrm{ml}$ of saline, $B$. fragilis in $0.2 \mathrm{ml}$ of pre-reduced HBSS, or both, were added to the fibrinogen solution before clotting with thrombin (Parke-Davis, Morris Plains, NJ) $6 \mathrm{U}$ in $0.2 \mathrm{ml}$. In monomicrobial clots, the appropriate control vehicle was used to replace the synergic bacterial partner. In studies examining the ability of $B$. fragilis culture supernates to act synergically with $E$. coli, $0.2 \mathrm{ml}$ of filter-sterilised 24-h cultures of $B$. fragilis or sterile culture broth were substituted for the inoculum of $B$. fragilis. For some studies, bacteria (either E. coli or B. fragilis VPI 9032) were heat-killed by boiling for $15 \mathrm{~min}$. Killing was confirmed by aerobic and anaerobic culture. Bacterial numbers were adjusted by counting in a Petroff-Hauser chamber followed by appropriate dilution.

\section{Fibrin-clot peritonitis model}

Male Wistar rats, weighing $200-250 \mathrm{~g}$, were inoculated intraperitoneally (i.p.) with infected fibrin clots as previously described (Rotstein et al., 1985). Briefly, a single clot was inserted i.p. into a rat under halothanenitrous oxide anaesthesia via a midline incision. The incision was closed with clips. Total anaesthesia time was 4-6 min. Animals were weighed daily and deaths were recorded.

\section{Quantitation of viable bacteria in abscesses}

On day 7 , rats were killed by $\mathrm{CO}_{2}$ asphyxiation. At laparotomy, the peritoneal cavity was inspected for the presence of abscesses. Abscess formation in this model was defined as the presence of a single walled-off collection of purulent material. Swabs of the peritoneal cavity were always sterile. The abscess was excised aseptically, weighed, and carefully minced into a tube containing prereduced HBSS and sterile glass beads held under a VPI anaerobe apparatus (Holdeman et al., 1977; Wells et al., 1985). The tube was stoppered, vortex mixed, and transferred to an anaerobic chamber. The tube contents were then serially diluted in prereduced HBSS and surface plated in duplicate on supplemented Brain Heart Infusion Agar (BHIA; Difco Laboratories, Detroit, MI) and nutrient agar (NA). The supplemented BHIA plates were incubated anaerobically at $35^{\circ} \mathrm{C}$ for $48 \mathrm{~h}$ and the NA plates were incubated aerobically at $37^{\circ} \mathrm{C}$ for $24 \mathrm{~h}$. The numbers of viable bacteria were quantitated and converted to $\log _{10}$ values. The limit of detection of bacteria in abscesses was $2.7 \log _{10} \mathrm{cfu} / \mathrm{ml}$.

\section{Statistical analysis}

Data on abscess weights and viable bacterial numbers in abscesses were analysed by a one-way analysis of variance and differences between groups were tested by Student's $t$ test.

\section{Results}

\section{Mortality}

The mortality rate throughout these studies was low and varied according to the bacterial inoculum. Monomicrobial $E$. coli inocula $\left(2 \times 10^{6}\right.$ or $2 \times 10^{7}$ $\mathrm{cfu} / \mathrm{clot}$ ) resulted in no deaths amongst 76 animals and $B$. fragilis $2 \times 10^{9} \mathrm{cfu} / \mathrm{clot}$ did so on only one occasion $(\sim 5 \%)$. The combination of E. coli $2 \times 10^{6}$ or $2 \times 10^{7} \mathrm{cfu} /$ clot plus $B$. fragilis $2 \times 10^{9} \mathrm{cfu} / \mathrm{clot}$ caused death in 4 out of 31 animals $(13 \%)$. The simultaneous inoculation of $E$. coli $2 \times 10^{7} \mathrm{cfu}$ i.p. within a fibrin clot with $B$. fragilis $2 \times 10^{7}$ cfu administered either free i.p., subcutaneously, intravenously or in a separate i.p. fibrin clot resulted in a mortality rate of $19 \%$ (11 out of 58$)$. Lower inocula of $B$. fragilis enmeshed with $E$. coli $2 \times 10^{7} \mathrm{cfu} / \mathrm{clot}$ did not cause death in 24 animals. Finally, $E$. coli $2 \times 10^{7}$ cfu mixed with either dead $B$. fragilis, sterile culture medium or $B$. fragilis culture filtrate caused a $12 \%$ mortality rate (6 out of 49 ). Animals who died before the 7-day evaluation were not assessed for abscess formation and were thus excluded from further analysis.

\section{Effect of mixed infection on abscess formation and bacterial numbers}

An inoculum of $E$. coli $2 \times 10^{7} \mathrm{cfu} /$ clot produced abscesses in $80 \%$ (41 out of 52 ) of animals. These 
abscesses were generally small and contained low numbers of $E$. coli $\left(3.2\right.$ SD $\left.0.5 \log _{10} \mathrm{cfu} / \mathrm{ml}\right) . B$. fragilis-infected clots, at the highest inoculum tested $\left(2 \times 10^{9} \mathrm{cfu} / \mathrm{clot}\right)$, frequently caused abscesses $(94 \%$, 17 out of 18) and these contained large numbers of bacteria (7.8 SD 0.6 $\log _{10} \mathrm{cfu} / \mathrm{ml}$ ) (table I). At all the lower inocula tested, $B$. fragilis did not produce true abscesses. Any abscesses seen were small $(0 \cdot 03-0 \cdot 1 \mathrm{~g})$ and consisted of a residual fibrin nidus which was frequently sterile, rather than the welldefined abscesses with a central purulent area and a collagenous capsule produced by high $E$. coli or B. fragilis inocula.

The addition of high doses of $B$. fragilis $\left(2 \times 10^{9}\right.$ cfu) to $E$. coli $\left(2 \times 10^{7} \mathrm{cfu}\right)$ in the fibrin clot inoculum resulted in significantly larger abscesses than were produced with either $E$. coli or $B$. fragilis alone $(\mathrm{p}<$ 0.05 ). The abscesses were quantitatively more purulent than monomicrobial abscesses and had higher numbers of $E$. coli $\left(7 \cdot 4 \mathrm{SD} 0 \cdot 3 \log _{10} \mathrm{cfu} / \mathrm{ml}\right.$ vs $\left.3.2 \mathrm{SD} 0.5 \log _{10} \mathrm{cfu} / \mathrm{ml} ; \mathrm{p}<0.0001\right)$. B. fragilis numbers were increased in mixed abscesses but differences were not statistically significant.

At intermediate doses of $B$. fragilis a reciprocal synergic relationship between $E$. coli and $B$. fragilis was demonstrated. There were significantly greater numbers of viable $E$. coli in abscesses initiated with a mixture of E. coli and B. fragilis $\left(2 \times 10^{7} \mathrm{cfu} / \mathrm{clot}\right.$ or $\left.2 \times 10^{5} \mathrm{cfu} / \mathrm{clot}\right)$ than in abscesses initiated by $E$. coli alone (5.4 SD $0.3 \log _{10} \mathrm{cfu} / \mathrm{ml}$ and $5.5 \mathrm{SD} 0.2$ $\log _{10} \mathrm{cfu} / \mathrm{ml}$ respectively for mixed abscesses $v s 3.2$ SD $0.5 \log _{10} \mathrm{cfu} / \mathrm{ml}$ for $E$. coli alone; $\left.\mathrm{p}<0.005\right)$. Furthermore, whereas $B$. fragilis inoculated alone at either of these doses resulted in small, frequently sterile abscesses, the presence of $E$. coli in the initial inoculum resulted in abscesses containing large numbers of $B$. fragilis.

The combination of $E$. coli plus $B$. fragilis at the lower inocula $\left(2 \times 10^{3} \mathrm{cfu} /\right.$ clot and $\left.2 \times 10^{2} \mathrm{cfu} / \mathrm{clot}\right)$ produced abscesses of similar size and with similar E. coli viable counts as those caused by $E$. coli alone. The ability of $E$. coli to increase survival of $B$. fragilis inoculated at $2 \times 10^{3} \mathrm{cfu} / \mathrm{clot}$ persisted, but the effect was less evident than at higher $B$. fragilis inocula.

\section{Effect of bacterial viability on E. coli-B. fragilis synergy}

To determine the role of bacterial viability on the production of $E$. coli-B. fragilis synergy, heatkilled $B$. fragilis were added to live $E$. coli in the fibrin clot inoculum (table II). Dead $B$. fragilis at inocula of $2 \times 10^{9}$ particles or $2 \times 10^{10}$ particles did not increase the weight of, or $E$. coli viable counts in, abscesses compared to $E$. coli alone, although mixed inocula containing $2 \times 10^{10}$ dead $B$. fragilis did result in significantly higher $E$. coli counts than those produced with $2 \times 10^{9}$ dead $B$. fragilis plus $E$. coli $(\mathrm{p}<0.01)$. Inoculation of dead $B$. fragilis alone did not result in abscess formation ( 6 animals were used for each dose). The data from two animals (one given $E$. coli plus $2 \times 10^{9}$ dead $B$. fragilis and one given $E$. coli plus $2 \times 10^{10}$ dead $B$. fragilis) were excluded from analysis because quantitative abscess counts revealed the presence of live $\boldsymbol{B}$. fragilis.

Table I. Abscess formation following intraperitoneal inoculation of fibrin clots infected with $E$. $\dddot{c o l i}$ or $B$. fragilis or both

\begin{tabular}{|c|c|c|c|c|c|}
\hline \multicolumn{2}{|c|}{ Bacterial inoculum (cfu) } & \multirow{2}{*}{$\begin{array}{l}\text { Number of rats with } \\
\text { abscesses/number } \\
\text { inoculated }(\%)\end{array}$} & \multirow{2}{*}{$\begin{array}{c}\text { Mean abscess weight, } \\
\text { g (SD) }\end{array}$} & \multicolumn{2}{|c|}{$\begin{array}{c}\text { Mean bacterial viable } \\
\text { counts, } \log _{10} \mathrm{cfu} / \mathrm{ml}(\mathrm{SD})\end{array}$} \\
\hline E. coli & B. fragilis & & & E. coli & B. fragilis \\
\hline $2 \times 10^{7}$ & 0 & $41 / 52(80)$ & $0.28(0 \cdot 15)$ & $3 \cdot 2(0 \cdot 5)$ & \\
\hline 0 & $2 \times 10^{9}$ & $17 / 18(94)$ & $0.31(0.19)$ & $\ldots$ & $7 \cdot 8(0 \cdot 6)$ \\
\hline 0 & $2 \times 10^{7}$ & $8 / 20(40)$ & $0.10(0.02)$ & $\ldots$ & $0.9(0.9)$ \\
\hline 0 & $2 \times 10^{5}$ & $3 / 4(75)$ & $0.03(0.03)$ & $\ldots$ & NG \\
\hline 0 & $2 \times 10^{3}$ & $0 / 4 \quad(0)$ & & $\ldots$ & $\ldots$ \\
\hline $2 \times 10^{7}$ & $2 \times 10^{9}$ & $22 / 23(96)$ & $0.62(0.35)^{*}$ & $7 \cdot 4(0.3) \dagger$ & $8.9(0 \cdot 2)$ \\
\hline $2 \times 10^{7}$ & $2 \times 10^{7}$ & $20 / 20(100)$ & $0.51(0.19)^{*}$ & $5 \cdot 4(0.3) \dagger$ & $7.9(0.4) \ddagger$ \\
\hline $2 \times 10^{7}$ & $2 \times 10^{5}$ & $8 / 8(100)$ & $0.47(0.09)^{*}$ & $5.5(0.2) \dagger$ & $8.5(0.2) \ddagger$ \\
\hline $2 \times 10^{7}$ & $2 \times 10^{3}$ & $8 / 8(100)$ & $0.38(0.11)^{*}$ & $3.0(0.9)$ & $4.9(1.4)$ \\
\hline $2 \times 10^{7}$ & $2 \times 10^{2}$ & $8 / 8(100)$ & $0.43(0.16)$ & $1 \cdot 2(1 \cdot 5)$ & $0.9(0.9)$ \\
\hline
\end{tabular}

$\mathrm{NG}=$ no growth

$* \mathrm{p}<0.05$ vs monomicrobial $E$. coli inoculum.

$\dagger \mathrm{p}<0.005$ vs monomicrobial $E$. coli inoculum.

$\ddagger \mathrm{p}<0.0001$ vs monomicrobial $B$. fragilis inoculum at same dose. 
Table II. Effect of dead B. fragilis on E. coli-B. fragilis abscess formation

\begin{tabular}{|c|c|c|c|}
\hline Bacterial inoculum* & $\begin{array}{l}\text { Number of } \\
\text { abscesses } \\
\text { evaluated }\end{array}$ & $\begin{array}{l}\text { Mean abscess } \\
\text { weight, } \\
\text { g (SD) }\end{array}$ & $\begin{array}{c}\text { Mean } E \text {. coli viable } \\
\text { counts in abscesses, } \\
\log _{10} \mathrm{cfu} / \mathrm{ml}(\mathrm{SD})\end{array}$ \\
\hline $\begin{array}{l}\text { E. coli } \text { alone } \\
\text { E. coli plus live } B \text {. fragilis }\end{array}$ & 7 & $0.32(0.26)$ & $3 \cdot 6(1.6)$ \\
\hline $\begin{array}{l}2 \times 10^{9} \mathrm{cfu} / \mathrm{clot} \\
\text { E. coli } \text { plus dead } B . \text { fragilis }\end{array}$ & 9 & $0.59(0.27) \S$ & $6.6(1.5) \dagger$ \\
\hline $\begin{array}{l}2 \times 10^{9} / \text { clot } \\
\text { E. coli plus dead } B \text {. fragilis }\end{array}$ & 7 & $0.27(0.21)$ & $2 \cdot 4(1 \cdot 1)$ \\
\hline $2 \times 10^{10} / \mathrm{clot}$ & 10 & $0.22(0 \cdot 32)$ & $4 \cdot 7(1.9) \ddagger$ \\
\hline
\end{tabular}

$*$ E. coli $2 \times 10^{7} \mathrm{cfu} / \mathrm{clot}$ in all cases.

$\dagger \mathrm{p}<0.02$ vs all other groups.

$\ddagger$ p, 0.01 vs $E$. coli plus dead $B$. fragilis $2 \times 10^{9}$; not significantly different from $E$. coli alone.

$\S \mathrm{p}<0.02$ vs both groups containing $E$. coli plus dead $B$. fragilis.

Interestingly, these abscesses were large and contained high numbers of both $E$. coli and $B$. fragilis.

In a reciprocal fashion, synergy was not demonstrated when $2 \times 10^{7}$ heat-killed $E$. coli and $2 \times 10^{7}$ cfu of live $B$. fragilis were inoculated together i.p. within a fibrin clot (data not shown).

\section{Effect of $B$. fragilis culture filtrates on $E$. coli abscess formation}

Filter-sterilised, 24-h culture filtrates of $B$. fragilis were added to $E$. coli fibrin clot inocula to determine whether a soluble by-product of $\boldsymbol{B}$. fragilis was responsible for $E$. coli-B. fragilis synergy. As shown in table III, $B$. fragilis filtrates did not increase abscess size or final $E$. coli numbers in abscesses when compared to $E$. coli alone or to $E$. coli combined with sterile culture medium.

Effect of the location of $B$. fragilis on its ability to act synergically with $E$. coli

To determine whether the mechanism of E. coli-
$B$. fragilis synergy required direct interaction between $E$. coli and $B$. fragilis, $B$. fragilis inocula were administrated by various routes simultaneously with the i.p. insertion of a fibrin clot containing $E$. coli $2 \times 10^{7}$. Table IV shows that synergy occurred only when $E$. coli and $B$. fragilis were both inoculated i.p. whether in the same clot, in separate clots or when $B$. fragilis was given free i.p. in the presence of an $E$. coli clot, although in the latter case figures did not reach statistical significance. In the 10 rats given $B$. fragilis and $E$. coli clots simultaneously i.p., there was always a single abscess present at 7 days and in nine of these animals the abscess contents contained both $E$. coli and $B$. fragilis in high numbers. In one animal, the abscess contained only $E$. coli; the abscess was small and $E$. coli viable counts were low $\left(3 \cdot 3 \log _{10}\right.$ $\mathrm{cfu} / \mathrm{ml})$. When an $E$. coli-infected clot was coinoculated i.p. with a sterile fibrin clot, single abscesses were present in three out of four animals. These were small $(0.16$ SD $0.09 \mathrm{~g})$ and contained low numbers of $E$. coli $\left(2 \cdot 2 \mathrm{SD} 2 \cdot 0 \log _{10} \mathrm{cfu} / \mathrm{ml}\right)$.

Table III. Effect of $B$. fragilis culture filtrates on E. coli abscess formation

\begin{tabular}{|c|c|c|c|}
\hline Bacterial inoculum* & $\begin{array}{l}\text { Number of } \\
\text { abscesses } \\
\text { evaluated }\end{array}$ & $\begin{array}{l}\text { Mean abscess } \\
\text { weight, } g(\mathrm{SD})\end{array}$ & $\begin{array}{l}\text { Mean } E \text {. coli viable counts } \\
\text { in abscesses, } \log _{10} \mathrm{cfu} / \mathrm{ml} \\
\text { (SD) }\end{array}$ \\
\hline $\begin{array}{l}\text { E. coli alone } \\
\text { E. coli plus } B \text {. fragilis }\end{array}$ & 4 & $0 \cdot 18(0 \cdot 12)$ & $2 \cdot 1(1 \cdot 4)$ \\
\hline $2 \times 10^{9} \mathrm{cfu} / \mathrm{clot}$ & 3 & $0.45(0.12) \dagger$ & $7 \cdot 2(1 \cdot 4) \ddagger$ \\
\hline $\begin{array}{l}E \text {. coli plus sterile medium } \\
E \text {. coli plus } B \text {. fragilis }\end{array}$ & 8 & $0 \cdot 27(0 \cdot 11)$ & $3.7(1.4)$ \\
\hline culture filtrate & 7 & $0 \cdot 20(0 \cdot 11)$ & $3 \cdot 3(1 \cdot 3)$ \\
\hline
\end{tabular}

\footnotetext{
* E. coli $2 \times 10^{6} \mathrm{cfu} / \mathrm{clot}$ in all groups.

$\dagger \mathrm{p}<0.05$ vs all other groups.

$\ddagger \mathrm{p}<0.01$ vs all other groups.
} 
Table IV. Effect of the location of $B$. fragilis inoculation on production of $E$. coli-B. fragilis synergy

\begin{tabular}{|c|c|c|c|}
\hline \multirow[b]{2}{*}{ Bacterial inoculum* } & \multirow{2}{*}{$\begin{array}{l}\text { Number of rats with } \\
\text { abscesses/numbèr } \\
\text { inoculated (\%) }\end{array}$} & \multicolumn{2}{|c|}{$\begin{array}{l}\text { Mean bacterial viable } \\
\text { counts, } \log _{10} \mathrm{cfu} / \mathrm{ml}(\mathrm{SD})\end{array}$} \\
\hline & & E. coli & B. fragilis \\
\hline E. coli alone in clot & $3 / 6(50)$ & $2 \cdot 4(1 \cdot 0)$ & \\
\hline $\begin{array}{l}\text { B. fragilis alone in clot } \\
\text { E. coli plus } B \text {. fragilis }\end{array}$ & $1 / 4(25)$ & $\ldots$ & NG \\
\hline $\begin{array}{l}\text { in same clot } \\
\text { E. coli in clot plus }\end{array}$ & $6 / 6(100)$ & $5 \cdot 6(0.7) \ddagger$ & $8.4(0 \cdot 7)$ \\
\hline $\begin{array}{l}\text { B. fragilis free i.p. } \dagger \\
\text { E. coli plus } B \text {. fragilis }\end{array}$ & $4 / 4(100)$ & $4.9(0.9)$ & $7 \cdot 3(0 \cdot 8)$ \\
\hline $\begin{array}{l}\text { in separate clots } \\
E . \text { coli in clot plus }\end{array}$ & $10 / 10(100)$ & $5 \cdot 5(0 \cdot 5) \ddagger$ & $6.9(0.5)$ \\
\hline $\begin{array}{l}\text { separate sterile clot } \\
E . \text { coli in clot plus }\end{array}$ & $3 / 4(75)$ & $2 \cdot 2(2 \cdot 0)$ & NG \\
\hline $\begin{array}{l}\text { B. fragilis i.v. } \dagger \\
\text { E. coli in clot plus }\end{array}$ & $4 / 4(100)$ & $1 \cdot 1(0 \cdot 9)$ & NG \\
\hline B. fragilis s.c. in clot & $2 / 3(66)$ & $3 \cdot 8(1 \cdot 2)$ & NG \\
\hline
\end{tabular}

These data suggest that the increased $E$. coli counts in abscesses initiated by double clot insertion were more likely to be due to bacterial interaction than the presence of a second intra-abdominal clot. In contrast, simultaneous intravenous or subcutaneous inoculation of $B$. fragilis did not act synergically with $E$. coli-containing clots given i.p. Abscesses were uniformly small and never contained $B$. fragilis.

\section{Discussion}

The importance of synergic bacterial interactions in determining the pathogencity of mixed infections has been demonstrated clearly in several model systems. Several mechanisms have been proposed to account for this relationship (Mackowiak, 1978). One bacterial species may promote the survival of its bacterial partner in a mixed infection by providing growth factors, impairing host defence mechanisms, optimising the local micro-environment, or by transferring virulence factors. Correlation between these proposed mechanisms and the in-vivo setting has received relatively little attention, particularly in relation to intra-abdominal infections. Reznikov et al. (1981) demonstrated that co-injection of $B$. fragilis with $E$. coli into the peritoneal cavity had no effect on the clearance of $E$. coli. These authors concluded that impaired phagocytosis of $E$. coli due to the presence of $B$. fragilis, a well defined in-vitro mechanism, was unlikely to be active in vivo. Studies by Dunn et al. (1985) demonstrated that non-viable $B$. fragilis were able to impair clearance of non-viable $E$. coli from the peritoneal cavity. However, non-viable $E$. coli were able to mimic the effect of $B$. fragilis, thereby implying that impaired clearance was a nonspecific effect mediated by large numbers of particles rather than a demonstration of $E$. coli-B. fragilis synergy. The inability to demonstrate synergy in these two studies may have been due to the rapid clearance of bacteria from the peritoneal cavity via the diaphragmatic lymphatics (Dunn et al., 1987), thereby not allowing the intimate interaction required for microbial synergy. Adjuvant materials such as sterile faeces and barium (Onderdonk et al., 1976), fibrin (Wells et al., 1985; Rotstein and Kao, 1988), and cellulose fibres (Hagen et al., 1983) which retard bacterial clearance, are generally required to demonstrate bacterial synergy in the peritoneal cavity.

Onderdonk et al. (1976) demonstrated synergy between $E$. coli and $B$. fragilis with respect to abscess formation using a model in which the bacterial inoculum was mixed with barium sulphate and sterilised rat faeces. These studies also showed that mortality in mixed infections correlated with the dose of $E$. coli in the inoculum. Subsequent 
studies with the fibrin clot peritonitis model confirmed these findings and, furthermore, demonstrated that $B$. fragilis could modulate the mortality rate (Rotstein et al., 1985). The ability of Bacteroides spp. to do so did not correlate with capsulation (Rotstein et al., 1987). The inoculum size and the particular strain of $E$. coli in the infecting inoculum may also determine whether $B$. fragilis is able to modulate $E$. coli-fibrin clot lethality (Wells et al., 1985; Rotstein and Kao, 1988).

In the present studies, we used the fibrin clot model of intra-abdominal infection to examine the synergic interactions between $E$. coli and $B$. fragilis with respect to abscess formation in vivo. This model closely mimics the clinical scenario in which an infected fibrinopurulent exudate represents an important precursor to abscess formation. In this model, the addition of $B$. fragilis to $E$. coli in the infecting inoculum approximately doubled the weight of the 7-day abscess and increased the residual number of $E$. coli by $2-4 \log _{10}$. In a reciprocal fashion, $E$. coli enhanced the persistence of $B$. fragilis. This was particularly evident with the lower $B$. fragilis inocula which alone resulted in a low rate of abscess formation with small abscesses and low bacterial numbers. The addition of $E$. coli to these inocula resulted in consistent formation of abscesses containing high numbers of $B$. fragilis. With higher inocula of $\boldsymbol{B}$. fragilis, the degree of purulence and the weight of the abscesses was again increased by the addition of $E$. coli. However, final $B$. fragilis numbers remained the same, probably because of limitation of bacterial growth within an abscess rather than a failure to demonstrate synergy.

The addition of $B$. fragilis at low inocula $\left(10^{2}\right.$ $\left.10^{3} \mathrm{cfu}\right)$ to $E$. coli in the fibrin clot resulted in abscesses no larger and containing no more $E$. coli than monomicrobial $E$. coli inocula. This threshold level of $\boldsymbol{B}$. fragilis for synergic abscess formation $\left(>2 \times 10^{3} \mathrm{cfu}\right.$ ) was several $\log _{10}$ values lower than that reported for synergic lethality with $E$. coli in this model ( $>3 \times 10^{7} \mathrm{cfu}$; Rotstein et al., 1987). The explanation for this difference probably lies in the different endpoints studied. Synergic lethality was characterised by an increase in mortality within the first 24-48 h. Thus, high $B$. fragilis inocula were required to facilitate the increased $E$. coli bacteraemia and subsequent increased mortality. In contrast, the prolonged interaction resulting in synergic abscess formation may have permitted lower initial inocula of $\boldsymbol{B}$. fragilis to act synergically.

Several mechanisms have been invoked as being important in the pathogenesis of aerobic-anaerobic bacterial synergy (Mackowiak, 1978). One mechanism, the ability of Bacteroides spp. to impair the phagocytic killing of aerobes by neutrophils, has received particular attention. Viable Bacteroides spp. are able to affect this phenomenon, whereas dead Bacteroides particles vary in their ability to do so. This depends on the method used to kill the bacteria. Boiling or killing with metronidazole removes the ability of Bacteroides spp. to impair phagocytic killing, but autoclaving at $115^{\circ} \mathrm{C}$ for 20 min has no effect (Ingham et al., 1981; Jones and Gemmell, 1982). To examine the requirements for live bacteria in the production of bacterial synergy in vivo, washed heat-killed $E$. coli or $B$. fragilis particles were substituted for live bacteria in mixed inocula with their live co-pathogens. Neither was able to reproduce the synergic effect of its viable counterpart. Since one might argue that $2 \times 10^{9}$ dead $B$. fragilis was an inappropriate substitute for $2 \times 10^{9}$ live $B$. fragilis because of the potential growth in vivo of the latter, we also studied the combination of $2 \times 10^{10}$ dead $B$. fragilis with live $E$. coli and were unable to demonstrate synergy. These findings are in agreement with those of Hite et al. (1949) in which heat killing of either 'Bacteroides', now Fusobacterium, necrophorum or Streptococcus liquefaciens before their combined inoculation at a subcutaneous site prevented bacterial synergy. The failure of $B$. fragilis heat-killed by boiling at $100^{\circ} \mathrm{C}$ for $10 \mathrm{~min}$ to act synergically with $E$. coli in vivo corresponds well with in-vitro studies demonstrating that $B$. fragilis cells killed by boiling lost their ability to impair the phagocytic killing of $E$. coli by neutrophils (Ingham et al., 1981). Further studies with $B$. fragilis killed by other methods are required to verify this correlation between the in-vivo and in-vitro setting. A number of studies have demonstrated that soluble factors in Bacteroides culture supernates may impair host defence mechanisms (Van Dyke et al., 1982; Namavar et al., 1983; Rotstein et al., 1986) but in the present study $B$. fragilis culture filtrates were unable to produce $E$. coli- $B$. fragilis synergy. This does not rule out the possibility that these factors diffused out of the fibrin mesh and were, therefore, unable to exert their synergic effect with $E$. coli in the fibrin clot. Conceivably, live $B$. fragilis mixed with $E$. coli might provide a local milieu in which these soluble factors are present in high concentrations for prolonged periods and are able to exert their effects.

A synergic relationship between $E$. coli and $B$. fragilis was evident when $B$. fragilis was inoculated within the peritoneal cavity together with an $E$. coli-infected clot, but not when $B$. fragilis was inoculated intravenously or subcutaneously. These results argue against inhibition of systemic host defences by $B$. fragilis as a mechanism for synergy 
as suggested by Rodloff et al. (1986). The consistent presence of both bacterial species within the abscesses when both were inoculated i.p. suggests the requirement for intimate local interaction between bacteria in the production of synergy. Interestingly, in the single animal which had a small abscess following i.p. inoculation with separate clots containing $E$. coli and $B$. fragilis, the abscess was monomicrobial, containing small numbers of $E$. coli. While it is unclear why cross-seeding of clots with bacteria resulting in synergy did not occur in this animal, the results further demonstrate the requirement of local interaction between bacteria in the production of synergy.

\section{REFERENCES}

Berne T V, Yellin A W, Appleman M D, Heseltine P N R 1982 Antibiotic management of surgically treated gangrenous or perforated appendicitis: comparison of gentamicin and clindamycin versus cefamandole versus cefoperazone. American Journal of Surgery 144: 8-13.

Brook I, Hunter V, Walker R I 1984 Synergistic effect of Bacteroides, Clostridium, Fusobacterium, anaerobic cocci, and aerobic bacteria on mortality and induction of subcutaneous abscesses in mice. Journal of Infectious Diseases 149: 924-928.

Delong T G, Simmons R L 1982 Role of the lymphatics in bacterial clearance from early soft-tissue infection. Archives of Surgery 117: 123-128.

Dunn D L, Barke R A, Ewald D C, Simmons R L 1985 Effects of Escherichia coli and Bacteroides fragilis on peritoneal host defenses. Infection and Immunity 48: 287-291.

Dunn D L, Barke R A, Ewald D C, Simmons R L 1987 Macrophages and translymphatic absorption represent the first line of host defense of the peritoneal cavity. Archives of Surgery 122: 105-110.

Gorbach S L 1984 Treatment of intraabdominal infection. American Journal of Medicine 76 Suppl 5A : 107-110.

Hagen J C, Wood W S, Hashimoto T 1983 Experimental intraabdominal abscess formation by Escherichia coli and Bacteroides fragilis. European Journal of Clinical Microbiology 2: 43-49.

Hite K E, Locke M, Hesseltine H C 1949 Synergism in experimental infection with nonsporulating anaerobic bacteria. Journal of Infectious Diseases 84 : 1-9.

Holdeman L V, Cato E P, Moore W E C 1977 Anaerobe Laboratory Manual, 4th edn. Anaerobe Laboratory, Virginia Polytechnic Institute and State University, Blacksburg, VA.

Ingham H R, Sisson P R, Middleton R L, Narang H K, Codd A A, Selkon J B 1981 Phagocytosis and killing of bacteria in aerobic and anaerobic conditions. Journal of Medical Microbiology 14: 391-399.

Jones G R, Gemmell C G 1982 Impairment by Bacteroides species of opsonization and phagocytosis of enterobacteria. Journal of Medical Microbiology 15: 351-361.

Kelly M J 1978 The quantitative and histological demonstration of pathogenic synergy between Escherichia coli and Bacteroides fragilis in guinea-pig wounds. Journal of Medical Microbiology 11 : 513-523.

Lorber B, Swenson R M 1975 The bacteriology of intra-
In conclusion, these studies have demonstrated a reciprocal synergic relationship between $E$. coli and $B$. fragilis in a relevant model of intra-abdominal infection. Studies examining the mechanisms underlying this phenomenon illustrate the complex nature of the local interactions between bacteria and their environment in determining the ultimate virulence of mixed infections. Further studies should attempt to examine mechanisms of synergy in vivo to verify their importance.

This work was supported by the Medical Research Council of Canada. The authors thank Miss Christina Wareham for preparation of the manuscript.

abdominal infection. Surgical Clinics of North America 55: 1349-1354.

Mackowiak P A 1978 Microbial synergism in human infections (second of two parts). New England Journal of Medicine 298 : 83-87.

MacLaren D M, Namavar F, Verweij-van Vught A M J J, Vel W A C, Kaan J A 1984 Pathogenic synergy: mixed intraabdominal infections. Antonie van Leeuwenhoek 50: 775787.

Namavar F, Verweij A M J J, Bal M, van Steenbergen T J, de Graaf J, MacLaren D M 1983 Effect of anerobic bacteria on killing of Proteus mirabilis by human polymorphonuclear leukocytes. Infection and Immunity 40: 930-935.

Onderdonk A B, Bartlett J G, Louie T J, Sullivan-Siegler N, Gorbach S L 1976 Microbial synergy in experimental intraabdominal abscess. Infection and Immunity 13: 22-26.

Onderdonk A B, Kasper D L, Cisneros R L, Bartlett J B 1977 The capsular polysaccharide of Bacteroides fragilis as a virulence factor: comparison of the pathogenic potential of encapsulated and unencapsulated strains. Journal of Infectious Diseases 136: 82-89.

Reznikov M, Finlay-Jones J J, McDonald P J 1981 Effect of Bacteriodes fragilis on the peritoneal clearance of Escherichia coli in mice. Infection and Immunity 32: 398-399.

Rodloff A C, Becker J, Blanchard D K, Klein T W, Hahn H, Freidman H 1986 Inhibition of macrophage phagocytosis by Bacteroides fragilis in vivo and in vitro. Infection and Immunity 52: 488-492.

Rotstein O D, Kao J 1988 The spectrum of Escherichia coliBacteroides fragilis pathogenic synergy in an intraabdominal infection model. Canadian Journal of Microbiology 34: 352357.

Rotstein O D, Pruett T L, Simmons R L 1985 Lethal microbial synergism in intra-abdominal infections: Escherichia coli and Bacteroides fragilis. Archives of Surgery 120: 146-151.

Rotstein O D, Pruett T L, Sorenson J J, Fiegel V D, Nelson R D, Simmons R L 1986 A Bacteroides by-product inhibits human polymorphonuclear leukocyte function. Archives of Surgery 121 : 82-88.

Rotstein O D, Pruett T L, Wells C L, Simmons R L 1987 The role of bacteroides encapsulation in the lethal synergy between Escherichia coli and Bacteroides species in a rat fibrin clot peritonitis model. Journal of Infection 15: 135146.

Shapiro M E, Kasper D L, Zaleznik D F, Spriggs S, Onderdonk A B, Finberg R W 1986 Cellular control of abscess formation: role of $T$ cells in the regulation of abscesses 
formed in response to Bacteroides fragilis. Journal of Immunology 137: 341-346.

Shapiro M E, Onderdonk A B, Kasper D L, Finberg R W 1982 Cellular immunity to Bacteroides fragilis capsular polysaccharide. Journal of Experimental Medicine 155: 1188-1197.

Van Dyke T E, Bartholemew E, Genco R J, Slots J, Levine M J

1982 Inhibition of neutrophil chemotaxis by soluble bacterial products. Journal of Periodontology 53: 502-508.

Verweij-van Vught A M J J, Namavar F, Sparrius M, Vel W A
C, MacLaren D M 1985 Pathogenic synergy between Escherichia coli and Bacteroides fragilis: studies in an experimental mouse model. Journal of Medical Microbiology 19: 325-331.

Wells C L, Arland L A, Simmons R L, Rotstein O D 1985 In vivo bactericidal activity of Sch 34343 in Bacteroides fragilis abscesses and in Bacteroides fragilis-Escherichia coli abscesses. Journal of Antimicrobial Chemotherapy 15 Suppl C: 199-206. 